\section{National survey of corneal abrasion treatment}

K. SABRI, J.C. PANDIT, V.T. THALLER, N.M. EVANS, G.R. CROCKER

\begin{abstract}
Purpose To survey the different methods used in the management of corneal abrasions (including iatrogenic cases) nationally. Method A questionnaire survey of all 162 ophthalmic units in the UK was carried out in 1997.

Results The response rate was 134 of 162 $(83 \%)$. The majority of units do not have an established policy for the treatment of corneal abrasions. Topical antibiotic alone and antibiotic together with a cycloplegic are the commonest immediate treatments, whilst the most common treatment course is topical antibiotic. Padding and patient follow-up is practised some of the time by most units and all of the time by the remaining minority. Use of a soft bandage contact lens is uncommon.

There is no statistically significant difference ( $p>0.05$ ) between the policy-holders and nonpolicy-holders in their use of the various topical regimes, padding and soft bandage contact lens.

Conclusion The traditional trio of topical antibiotic, cycloplegic and padding is still the mainstay of comeal abrasion treatment amongst units nation-wide. However, there is a lack of reproducible scientific evidence to support this treatment. Larger randomised trials looking at the efficacy of the different treatment options are needed.
\end{abstract}

K. Sabri

J.C. Pandit

V.T. Thaller

N.M. Evans

Royal Eye Infirmary

Plymouth

UK

\section{K. Sabri 2}

41 Elm Close

Mapperley Road

Notts NG3 5AH

UK

Tel: $+44(0) 1159249924$

\section{G.R. Crocker}

School of Mathematics and

Statistics

University of Plymouth

Plymouth

UK

Corneal abrasions are often painful, sometimes disabling but usually self-limiting. They form a common presenting problem in general ${ }^{1}$ and ophthalmic $^{2-7}$ casualties. To our knowledge no published data exist on the current pattern in the treatment of corneal abrasions.

Nevertheless, due to the prevalence of this condition, small variations in management will affect a significant proportion of casualty attenders and also their health costs.

\section{Aim}

The aim of this study was to survey the different methods used in the management of corneal abrasions (including iatrogenic cases) nationally.

\section{Method}

A short questionnaire was designed, covering all current aspects of corneal abrasion management including:

(a) existence of departmental policies

(b) which health staff decide on the type of treatment where no policy exists

(c) topical therapy and pad/soft bandage contact lens use

This section was divided into 'immediate treatment' (treatment given on the first visit to the hospital) and 'treatment course' (any continuing treatment prescribed for the patient)

(d) patient follow-up.

Topical anaesthetics were assumed to be used only for ocular examination and removal of corneal foreign bodies. They were not included in the questionnaire.

Respondents were asked to tick the appropriate option boxes and give short answers. A pilot study was carried out to validate the questionnaire. Next, forms (together with prepaid reply envelopes) were sent out to the remaining ophthalmic units ${ }^{8}$ in the country (England, Wales, Scotland and Northern Ireland) during February and March 1997. The questionnaires were directed to the nurse in charge of the ophthalmic or general casualties. After 2 weeks a second mailing to the non-responders was carried out.

\section{Results}

In total, 162 forms were sent out and 134 returned, representing a response rate of $83 \%$. At least half the units from each of the four home nations responded to the questionnaire. The non-respondents consisted of 22 peripheral hospitals and 6 university teaching hospitals. 
Table 1. Common topical therapentic regimes for cormeal abrasion

\begin{tabular}{|c|c|c|}
\hline & $\begin{array}{l}\text { Immediate } \\
\text { treatment" }\end{array}$ & $\begin{array}{c}\text { Treatment } \\
\text { course }^{a}\end{array}$ \\
\hline \multicolumn{3}{|l|}{ Policy-holders $(n=3())$} \\
\hline Antibiotic only & 10) $(3.3 \%)$ & $22\left(73^{\circ}{ }_{10}\right)$ \\
\hline Antibiotic and cycloplegic & $19(63 \%)$ & $4\left(13^{\prime \prime}\right)$ \\
\hline Others $^{b}$ & $1\left(3^{0} \%\right)$ & $4\left(13^{\circ} \%\right)$ \\
\hline \multicolumn{3}{|l|}{ Non-policy-holders $(n=104)$} \\
\hline Antibiotic only & $49(47 \%)$ & $72\left(69^{\prime \prime}\right)$ \\
\hline Antibiotic and cycloplegic & $43(41 \%)$ & $18\left(17^{\circ} "\right)$ \\
\hline Others & $12(12 \%)$ & $14\left(13^{\circ} \%\right)$ \\
\hline
\end{tabular}

The percentages in some parts of the tables do not add up to $100 \%$ due to rounding off errors.

a Treatment policy in the case of policy-holders; the most common treatment in the case of non-policy-holders.

bIncludes the collective minority of non-responders, units which use no treatment or cycloplegic only.

Only 30 of 134 units (22\%) have an established departmental policy for the management of corneal abrasions.

Amongst the non-policy-holders, management decisions are made by doctors alone in 75 of 104 units $(72 \%)$, by nursing staff only in 4 of 104 units $(4 \%)$ and by both in 25 of 104 units $(24 \%)$. Several different grades of staff may be involved in each department, the most common being the ophthalmic senior house officer (SHO) in 87 of 104 units $(84 \%)$ and the general casualty SHO in 57 of 104 units $(55 \%)$. The consultant ophthalmologist participates in decision-making in 21 of 104 units $(20 \%)$.

\section{Topical therapy (Table 1)}

The common immediate treatment regimes are antibiotic together with cycloplegic and antibiotic alone. The latter is also the most popular treatment course. No topical therapy is the treatment of choice for immediate treatment or course of treatment in less than $14 \%$ of policy-holders and $8 \%$ of non-policy-holders.

Cycloplegic alone is occasionally used, only by the non- policy-holders. Topical antibiotic used is in ointment form in $40-50 \%$ of units, and in either ointment or drop form in $30-40 \%$ of units (irrespective of existing policies).

\section{Pad/soft bandage contact lens use (Table 2)}

All departments advocate padding, either all or some of the time. Most padding is for 1-3 days. The majority of units never use a soft bandage contact lens whilst the remaining departments only use a lens in cases of recurrent corneal erosion. Pain relief, accelerated healing rate or both are all mentioned as benefits of padding and soft bandage contact lens use. In units where either padding or soft bandage contact lens is sometimes used the former is always more common.

\section{Follozv-up}

Regardless of existing policies, patient review is carried out by the ophthalmic SHO in $50-60 \%$ of units and the general casualty $\mathrm{SHO}$ in $30-40 \%$ of units. All patients are reviewed in 16 of 30 policy-holding units $(53 \%)$ and 17 of 104 non-policy-holding units $(16 \%)$. The remaining departments follow up some of the patients. The patients are reviewed within 3 days in 24 of 30 policy-holding units $(80 \%)$ and 56 of 104 non-policy-holding units (54\%).

\section{Discussion}

\section{Survey results}

The majority of units do not have an established policy for the treatment of corneal abrasions. Topical antibiotic alone and antibiotic together with cycloplegic are the commonest immediate treatments whilst the most common treatment course is topical antibiotic. Padding and patient follow-up is practised some of the time by most units and all of the time by the remaining minority. Use of a soft bandage contact lens is uncommon. Existence of policies makes no statistically significant

Table 2. Use of pad/soft bandage contact lens (sbl) for cormeal abrasion

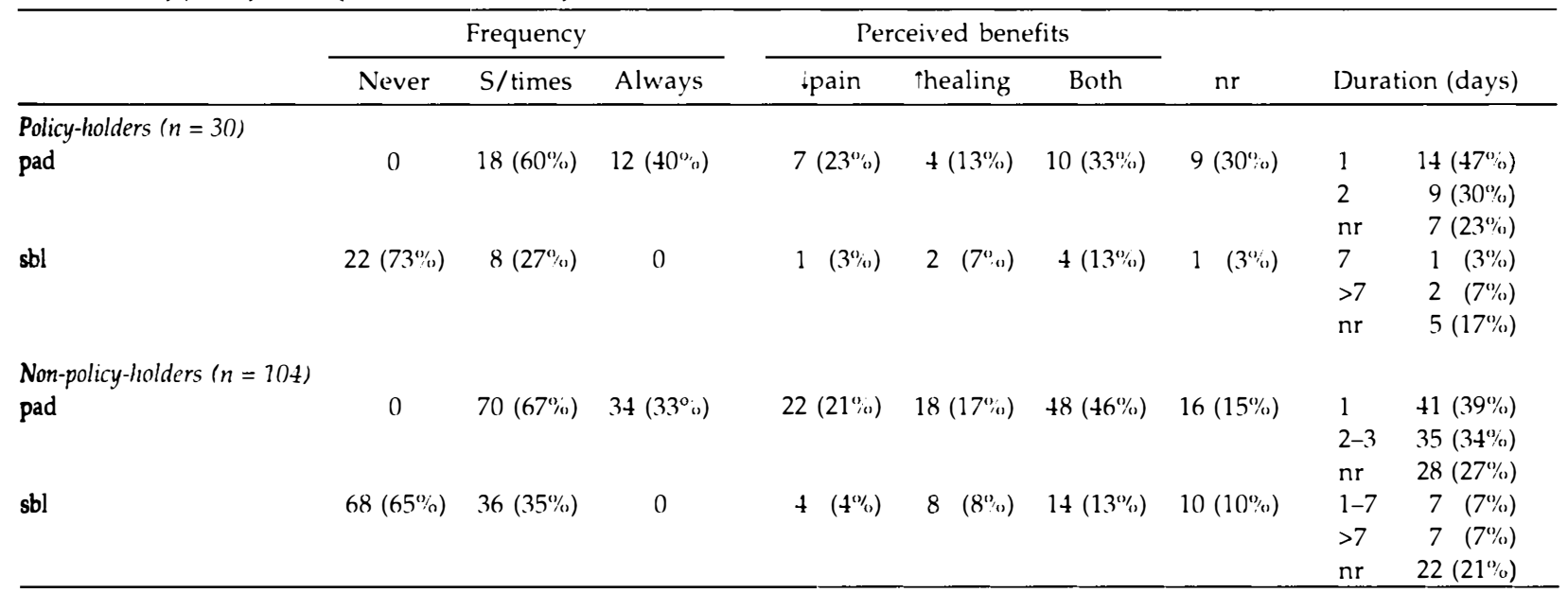

$\mathbf{n}$, non-responders to this section. 
difference ( $p>0.05$; Fisher's exact test) to the usage of the various topical regimes, padding or soft bandage contact lens.

\section{Historical background}

Treatment of corneal abrasions has been the subject of much interest and controversy for many decades. In the earlier part of this century corneal abrasions were a common cause of industrial injury and hence lost working time."-11

Amongst the earliest options used in treating corneal abrasions were topical antibiotics, cycloplegics and patching of the affected eye. ${ }^{10,11}$ This traditional management plan has persisted through to the present day, re-iterated as the treatment of choice by other authors over the decades. ${ }^{7,2-22}$ Topical anaesthetic drops have been shown to delay corneal epithelial healing. ${ }^{23-27}$

\section{Evidence-based practice?}

From early on, however, debates have existed over the theoretical benefits and potential harm of such traditional treatment. ${ }^{11}$ Whilst some treat all corneal abrasions with topical antibiotics, ${ }^{28}$ there is a lack of evidence supporting this practice. Topical antibiotics have been shown to impair corneal epithelial healing. ${ }^{29}$ Others ${ }^{30,31}$ have found no benefit in treating corneal abrasions with topical antibiotics.

It is often said that cycloplegia in all or some cases of corneal abrasion will reduce the ocular pain and inflammation by alleviating ciliary spasm. 7,12,14,20,21,32,33 However, despite an extensive literature search, no controlled study supporting this hypothesis could be found.

Padding is perhaps the most discussed issue in the treatment of corneal abrasions. While many argue that padding promotes pain relief, corneal healing (even advocating both eyes to be padded ${ }^{14,34}$ ) and prevention of bacterial contamination, others believe the reverse to be true and hence condemn its use. Padding the eye has been shown to be ineffective $\mathrm{e}^{35-37}$ or detrimental ${ }^{38-40}$ in pain relief and corneal healing. Some ${ }^{41}$ believe padding to provide a warm, moist environment for the growth of micro-organisms, although this is disputed by other studies. $^{42}$

With regard to follow-up there is no clear evidence as to which patients should be monitored. Some review all cases of corneal abrasion ${ }^{32}$ while others follow up abrasions secondary to foreign bodies only. ${ }^{18,21,41}$

\section{Other treatment methods}

Other means of managing corneal abrasions have also been investigated. Soft bandage contact lens ${ }^{6}$ has been shown to be significantly better than padding in reducing ocular pain and promoting corneal healing. There have, however, been concerns over the effect of such lenses on the corneal epithelium ${ }^{43,44}$ as well as their infection rates, cost and need for follow-up. Collagen shields ${ }^{45}$ are significantly more comfortable than padding. They may be particularly beneficial for the treatment of corneal abrasions in those with only one seeing eye (where vision is preserved) or contact lens wearers (where the administration of topical antibiotics is not hindered).

Topical non-steroidal anti-inflammatory drugs are being used as an alternative to padding for treating pain associated with corneal epithelial defects. ${ }^{46-48}$ Solcoseryl eye gel (Solco Basle, Birsfelden, Switzerland) ${ }^{49}$ and topical epidermal growth factor ${ }^{50}$ have also been associated with significantly improved healing times for corneal abrasions. These treatment modalities may be used more frequently in future if their efficacy is established.

\section{Financial implications}

Around 1800 cases of corneal abrasion are seen annually at the Royal Eye Infirmary in Plymouth. At a cost of 66p per patient for treatment with topical cycloplegic, antibiotic and pad, the total Plymouth Hospitals NHS Trust expenditure comes to $£ 1188$ each year. Assuming the patients are to pay for a course of topical antibiotic (£5.65 per prescription) the total cost to the population is $£ 10$ 170. Clearly, applied nation-wide, the costs to both patient and provider can be significant.

\section{Conclusion}

The traditional trio of topical antibiotic, cycloplegic and padding is still the mainstay of corneal abrasion treatment amongst units nation-wide (irrespective of the existence of policies). However, there is a lack of reproducible scientific evidence to support this treatment. Larger randomised trials are needed.

The management of corneal abrasions lends itself favourably to policy making. It is a common presenting problem in hospital casualties, is easily diagnosed and does not require sophisticated treatment. Based on the outcome of future research, national practice protocols may be formulated and put into practice. This could reduce wasteful expenditure on ineffective treatments and make patient review more selective, thus reducing costs to patient and provider alike. Furthermore, with clear policies in place, the management of corneal abrasions can be restructured so that the nursing staff and perhaps general practitioners play an increasingly active role in the diagnosis, treament and follow-up of patients.

\section{References}

1. Edwards RS. Ophthalmic emergencies in a district general hospital casualty department. Br J Ophthalmol 1987;71:938-42.

2. Vernon SA. Analysis of all new cases seen in a busy regional centre ophthalmic casualty department during a 24-week period. J R Soc Med 1983;76:279-82. 
3. Jones NP, Hayward JM, Khaw PT, Claoue CM, Elkington AR. Function of an ophthalmic 'accident and emergency' department: results of a six month survey. BM] 1986;292:188-90).

4. Sheldrick JH, Vernon SA, Wilson A, Read SJ. Demand incidence and episodes rates of ophthalmic disease in a defined urban population. BMJ 1992;305:933-6

5. Chaipella AP, Rosenthal AR. One year in an eye casualty clinic. Br J Ophthalmol 1985;67:865-7().

6. Acheson JF, Joseph J, Spalton DJ. Use of soft contact lenses in an eye casualty department for the primary treatment of traumatic corneal abrasions. Br J Ophthalmol 1987;71:285-9.

7. Knox KA, Mcintee J. Nurse management of corneal abrasion. Br J Nurs 1995;4:44()-60)

8. The directory of training in ophthalmology. 4th ed. London: Hawker, 1996.

9. Cridland $B$. The prevention of minor eye injuries in industry. Trans Ophthalmol Soc UK 1929;XLIX:206-21.

10. Minton J. Industrial eye injuries and their prevention. $\mathrm{Br}$ J Ophthalmol 1936;2():673-82.

11. MacRae A. Injuries to the eyeball, excluding intra-ocular foreign bodies. Trans Ophthalmol Soc UK 1945;LXV:3()5-17.

12. Duke-Elder S. Textbook of ophthalmology, vol VI. London: Henry Kimpton, 1954:5993-8.

13. Duke-Elder S, Leigh AG. System of ophthalmology, vol VIII(2). London: Henry Kimpton, 1965:696-7.

14. Duke-Elder S, MacFaul PA. System of ophthalmolog!, vol XIV(1). London: Henry Kimpton, 1972:476

15. Keeney AH. Evaluation and management of corneal foreign bodies. J Fam Pract 1975;2:381-4.

16. Wolf MA. The management of corneal abrasions and corneal foreign bodies. Occup Health Nurs 1981;29:32-3.

17. Newell SW. Management of corneal foreign bodies. Am Fam Physician 1985;31:149-56.

18. Reich JA. Removal of corneal foreign bodies. Aust Fam Physician 199();19:719-21.

19. Melton NR, Maino JH, Thomas RK. Management of corneal abrasions. Optom CIin 1991;1:119-26.

20. Fraunfelder FT, Hampton Roy F, Grove J. Current ocular therapy. $4^{\text {th }}$ ed. Philadelphia: WB Saunders, 1995:39()-1

21. Newell FW. Ophthalmology principles and concepts. $8^{\text {th }}$ ed. St Louis: Mosby 1996:184-5

22. Torok PG, Mader TH. Corneal abrasions. Am Fam Phy'sician 1996;53:2521-9.

23. Gundersen T, Liebman SD. Effect of local anaesthetics on regeneration of corneal epithelium. Arch Ophthalmol 1944;31:29-33.

2. Leuenberger PM. Ultrastructurelle Veranderungen am Hornhautepithel nach Oberflachenanesthesie. Graefes Arch Klin Ophthalmol 1973;186:73-90).

25. Hamisch JP, Hoffman F, Dumitrescu L. Side effects of local anaesthetics on the corneal epithelium of the rabbit eye. Graefes Arch Klin Arch Ophthalmol 1975;197:71-81.

26. Pfister RR, Burstein NL. The effects of ophthalmic drugs, vehicles and preservatives on corneal epithelium: a scanning electron microscope study. Invest Ophthalmol 1976;15:246-59.

27. Burstein NL, Klyce SD. Electrophysiologic and morphological effects of ophthalmic preparations on rabbit corneal epithelium. Invest Ophthalmol Vis Sci 1977;16:899-911.
28. Jayamanne DGR, Bell RWD. Non-penetrating corneal foreign body injuries: factors affecting delay in rehabilitation of patients. J Accid Emerg Med 1994;11:195-7.

29. Stern GA, Schemmer GB, Farber RD, Gorovoy MS. Effect of topical antibiotic solutions on corneal epithelial wound healing. Arch Ophthalmol 1983;101:644-7.

30. Kruger RA, Higgins J, Rashford S, Fitzgerald B, Land R. Emergency eye injuries. Aust Fam Physician 1990;19:934-8.

31. King JWR, Brison RJ. Do topical antibiotics help corneal epithelial trauma? Can Fam Physician 1993;39:2349-52.

32. Goodenberger D, Greer D. Ophthalmic emergencies. Top Emerg Med 1984;6:1-18.

33. Easty DL. Is an eye pad needed in cases of corneal abrasion? BMJ 1995;3()7:1(122.

34. Gregersen PL, Ottavay $\mathrm{E}$, Kobayashe C, Hansen SE, Bohnstedt J. Treatment of corneal abrasions. Ugeskr Laeger 1991;153:2123-4

35. Jackson H. Effect of eye-pads on healing of simple corneal abrasions. BMJ 1960);11:713.

36. Rao GP, Scott JA, King A, Blyth C, Ramesh A, Neoh C, Kaye SB. Letter to the editor. Eye 1994;8:371-2

37. Patterson J, Fetzer D, Krall J, Wright E, Heller M. Eye patch treatment for the pain of corneal abrasion. South Med J 1996;89:227-9.

38. Tisher PW. Industrial injuries of the eye caused by flying objects. Arch Ophthalmol 1945;33:152-4.

39. Hulbert MFG. Efficacy of eye pad in corneal healing after corneal foreign body removal. Lancet 1991;337:643.

4). Kirkpatrick JNP, Hoh HB, Cook SD. No eye pad for corneal abrasion. Eye 1993;7:468 71.

41. Scheie HG, Albert DM. Textbook of ophthalmology. $9^{\text {th }}$ ed. Philadelphia: WB Saunders, 1977:562-3.

42. Laws DE, Watts MT, Kirkby GR, Lawson J. Is padding necessary after cataract extraction? Br J Ophthalmol 1989;73:699-70)1.

43. Hamano $H$, Masaki $H$. Effect of contact lens wear on the mitosis of corneal epithelial cells. Contact Intraoc Lens Med J 1983;9:133-6.

44. Bergmanson JPG, Ruben CM, Chu LWF. Epithelial morphological response to soft hydrogel contact lenses. $\mathrm{Br} \mathrm{J}$ Ophthalmol 1985;69:373-9

45. Wedge CI, Rootman DS. Collagen shields: efficacy, safety and comfort in the treatment of human traumatic corneal abrasion and effect on vision in healthy eyes. Can J Ophthalmol 1992;27:295-8

46. Hersh PS, Rice BA, Baer JC, Wells PA, Lynch SE, McGuigan LJ, Foster CS. Topical non-steroidal agents and corneal wound healing. Arch Ophthalmol 199();108:577-83.

47. Solomon LD, ed. Proceedings of the ophthalmic NSAID roundtable: at the American Academy of Ophthalmology's 96th annual meeting. 2nd ed. Montreal: Medicopea, 1994:28.

48. Salz JJ, Reader AL, Schwartz LJ, Van Le K. Treatment of corneal abrasions with soft contact lenses and topical diclofenac. J Refract Corneal Surg 1994;10:64()-6.

49. Erbe W, Herrmann R, Korner WF, Rohde-Germann H, Straub $W$. Our experience with Solcoseryl Eye-Gel in the treatment of corneal lesions. Ophthalmologica 1984;188:1-4.

50. Pastor JC, Calonge M. Epidermal growth factor and corneal wound healing: a multicentre study. Cornea 1992;11:311-4. 